\title{
CARTA ABERTA À MARÍLIA
}

Glauce Souza Santos

Resumo: Nesta carta, endereçada à Marília, minha psicanalista, e a todas as mulheres negras, reflito sobre a pesquisa que realizo no doutoramento. Faço isso, resgatando cenas de uma sessão específica, na qual, Marília fez, para mim, o que denomino sugestão-desafio, escrever sobre a importância do meu trabalho. Assim, confesso as minhas inseguranças diante da minha escrita e tento encontrar respostas para o fato de nem sempre estar convicta a respeito da sua relevância. Inspirada na carta que Audre Lorde (2019) fez para a sua terapeuta e na carta de Gloria Anzaldúa (2000) às mulheres escritoras do terceiro milênio, penso sobre a interação que há entre mim e Marília, e sobre o que me motiva a escrever. Ressalto sobre o investimento dos trabalhos artísticos de Tássia Reis, Preta Rara e NegaFya, na expressão de uma existência negra feminina distanciada da ideia de um eu desqualificado, e como esses trabalhos me ajudam a perceber um caminho para minha própria vida, pois, situam os corpos femininos negros e suas subjetividades no centro dos seus discursos. Nessa linha, aciono Guerreiro Ramos (1995) para tencionar a ideia de objetos de estudo, cuja realidade e identidade são definidas por outros, e Donna Haraway (1995) para refletir sobre os saberes localizados que requerem que o objeto do conhecimento seja visto como um ator e agente. Outra reflexão que faço é a respeito da minha relação com a música e a minha legitimação como pesquisadora no campo musical. Ainda aciono a noção de escrevivência, cunhada por Conceição Evaristo, para discutir sobre o desafio que é incluir o pessoal e o subjetivo como parte do discurso acadêmico, tendo em vista que a pessoalidade e subjetividade mais aceita na academia é aquela produzida pelo sujeito branco.

Palavras-Chave: Escrita; Pesquisa; Eu; Mulheres negras; Subjetividade; Afeto

Abstract: In this letter, addressed to Marília, my psychoanalyst, and to all black women, I reflect about research taht I realize in my doctorate. I do this, revisiting scenes from a specific session, in which, Marília did, for me, whose I call suggestion-challenge, to write about the importance of my work. Thus, I confess my insecurities about my writing and try to find answers to the fact that I am not always convinced about its relevance. Inspired by the letter that Audre Lorde (2019) made to her therapist and 
Gloria Anzaldúa's letter (2000) to women writers of the third millennium, I think about the interaction that exists between me and Marilia, and about what motivates me to write. I emphasis on the investment of the artistic works by Tássia Reis, Preta Rara and NegaFya, in the expression of a black female existence distanced from the idea of a disqualified self, and how these works help me to understand a path for my own life, because they situate the black female bodies and their subjectivities at the center of their discourses. In this line, I engage Guerreiro Ramos (1995) to intend the idea of objects of study, whose reality and identity are defined by others, and Donna Haraway (1995) to reflect about localized knowledge that requires the object of knowledge to be seen as a actor and agent. Another reflection that I make is about my relationship with music and my legitimacy as a researcher in the musical field. I still activate the notion of "escrevivência", coined by Conceição Evaristo, to discuss the challenge of including the personal and the subjective as part of the academic discourse, considering that the most accepted personality and subjectivity in the academy is that produced by the white person.

Keywords: Writing; Research; Myself; Black women; Subjectivity; Affection.

Jequié, 21 de dezembro de 2020.

Querida Marília,

Resolvi fazer esta carta, depois de uma sessão de terapia, na qual você me incentivou a escrever sobre a importância da minha escrita. Sobre a importância do trabalho acadêmico que venho desenvolvendo no doutorado. Lembro-me que seu incentivo surgiu quando te falei que fui gestada quando minha mãe estava com as trompas ligadas. É, um verdadeiro milagre! Tanto que quando completei vinte e seis anos de idade, tomada por esta compreensão, escrevi o seguinte poema: 
Há vinte e seis anos ultrapasso os nós da vida os primeiros, foram os das trompas da minha mãe.

Então, na sessão, mesmo sem conhecer esse meu poema, você me disse algo, demostrando perceber que os desafios fazem parte da minha vida desde quando fui fecundada e perceber que o meu trabalho, assim como a ultrapassagem que fiz nas trompas da minha mãe, também ultrapassa diversos entraves no campo do conhecimento. Concordo muito com você, mas, confesso que nem sempre estou tão convicta sobre a importância do que faço, e sempre me pego questionando: o meu trabalho tem mesmo relevância?

Já que os nossos corpos e subjetividades negros experimentaram/experimentam (pois ainda morremos mais) atos desumanos e brutalizados, não é novidade que trabalhos como o meu sejam visto como menores ou sem relevância, e em alguns momentos, até mesmo por nós que os produzimos. Marília, as suspeitas que às vezes lanço sobre a minha escrita, e consequentemente, as punições que me dou e o dedo que me aponto, simplesmente porque estou embebida com a visão dos brancos, estão expressos naquele poema de Cuti, intitulado Quebranto, que li para você em um dos nossos encontros. Resolvi transcrevê-lo aqui: 


\section{Quebranto}

às vezes sou o policial que me suspeito me peço documentos e mesmo de posse deles me prendo e me dou porrada

às vezes sou o porteiro não me deixando entrar em mim mesmo a não ser pela porta de serviço

às vezes sou o meu próprio delito o corpo de jurados a punição que vem com o veredito às vezes sou o amor que me viro o rosto o quebranto o encosto a solidão primitiva que me envolvo com o vazio

às vezes as migalhas do que sonhei e não comi outras o bem-te-vi com olhos vidrados trinando tristezas

um dia fui abolição que me lancei de supetão no espanto depois um imperador deposto a república de conchavos no coração e em seguida uma constituição que me promulgo a cada instante também a violência dum impulso que me ponho do avesso com acessos de cal e gesso chego a ser 


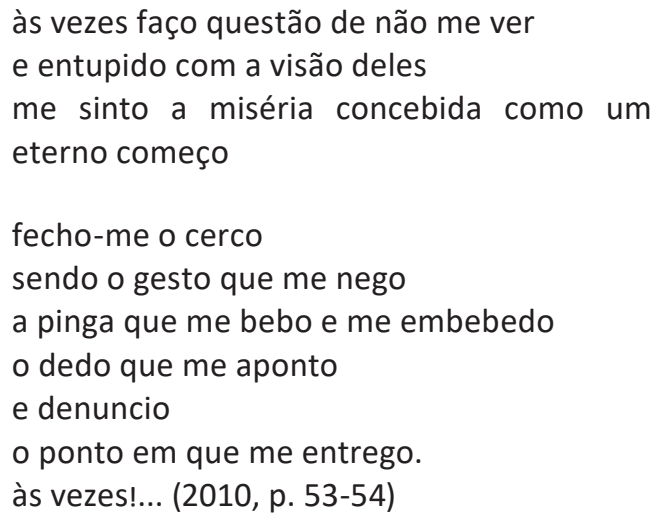

Diante das porradas que às vezes me dou, a sua sugestão, de eu escrever sobre a importância da minha escrita, chega para mim não apenas como uma mera sugestão, mas como uma sugestão-desafio que nasce numa interação atravessada por nossas semelhanças. O que existe entre nós, como mulheres negras, sem dúvida, nos afeta, e afeta ao trabalho que realizamos juntas. Para mim, tem surtido muitos efeitos. Esta carta, inclusive, é resultado dessa interação.

Além de seu incentivo para escrever este texto, busquei inspiração em uma carta que Audre Lorde escreveu para a psicanalista dela que, assim como você, era uma mulher negra. Nesta carta, publicada no livro Irmã Outsider (2019) há um tom de união em busca de entender mais a fundo como o que existia entre elas, como mulheres negras, afetava as duas e ao trabalho que realizavam juntas. Outra inspiração para o meu texto vem de Gloria Anzaldúa que 
escreveu Falando em línguas: uma carta para as mulheres escritoras do terceiro mundo (2000), texto, no qual, fala das intercorrências do dia a dia no ato da escrita das mulheres negras “[...] Por que escrever parece tão artificial para mim? Eu faço qualquer coisa para adiar este ato - esvazio o lixo, atendo o telefone" (2000, p. 230), sem deixar de registrar o poderoso efeito das nossas escritas: registrar nossas falas e reescrever as histórias mal escritas sobre nós. O texto de Anzaldúa me inspira a pensar o que me motiva a escrever e qual a importância do que escrevo. O mais importante é que também me faz perceber que eu não estou só. Que escrever para você, por exemplo, é uma forma de dissipar a solidão da escrita e a sensação da falta de poder. Que as inconstâncias, as dúvidas, as inseguranças e a resistência ao ato de escrever, ao compromisso da escrita tem um sentido porque "Escrever é confrontar nossos próprios demônios, olhá-los de frente e viver para falar sobre eles" (ANZALDUÁ, 2000, p. 234).

Marília, eu preciso te dizer algo que nunca te disse. Quando resolvi retornar à terapia, um dos meus pré-requisitos era retornar ao tratamento com uma profissional negra. E esse critério dizia respeito não apenas à pigmentação da pele, características fenotípicas e estéticas, mas também ao se ler negra. Desde o nosso primeiro encontro ficou evidente, para 
mim, que você se lê como negra. Ressalto isso porque ter uma escuta profissional como a sua significa que não corro mais o risco de ouvir da boca de uma terapeuta se as experiências violentas relacionadas à cor da minha pele, relatadas por mim, não eram apenas uma mera impressão.

Quando você me fez a sugestão-desafio e eu decidi escrever essa carta, automaticamente me lembrei de uma provocação feita a mim, por Lívia Natália (minha orientadora): "para quem você está escrevendo?". Então, eis a resposta: o meu texto é para todas as Marílias, para todas as mulheres negras. É a elas a quem escrevo. Sobretudo, o meu texto é uma resposta para mim mesma. Confesso mais uma vez que por diversas vezes sinto-me insegura sobre o trabalho que desenvolvo, um trabalho totalmente vinculado ao tema do poder de fala, da inscrição de corpos negros femininos e da importância das subjetividades negras, um trabalho desenvolvido numa universidade que apenas há menos de duas décadas tem aberto as portas para nós, negros e negras, e para as nossas pesquisas, um trabalho que se dá entre outros trabalhos e tensões, pois, boa parte da minha formação intelectual se dá, concomitante, à carreira do ensino, às outras obrigações e aos conflitos familiares. Porém, confesso: adoraria que não fosse assim. Adoraria não ter que lidar com todo esse sofrimento. Mas, como 
diz bell hooks (1995), é um processo prazeroso e extático andar em meio a esse sofrimento para trabalhar com ideias que possam servir de catalisadoras para a transformação de nossa consciência e nossas vidas e de outras pessoas. Essa é uma das alegrias do meu trabalho.

Como já te falei, Tássia Reis, Preta Rara e Nega Fya são mulheres negras, são as sujeitas da minha pesquisa. Eu prefiro chamá-las assim, pois, essas artistas demonstram para mim que são definidoras das suas próprias realidades. Com suas produções, elas estabelecem suas próprias identidades e nomeiam suas histórias. Portanto, estão longe de serem meros objetos de estudo, cuja realidade e identidade são definidas por outros. Estão longe de serem o negro-tema, como nos alertou Guerreiro Ramos, essa "[...] coisa olhada, examinada, mumificada, o contrário do Negro-vida" (1995, p. 215). Chamá-las assim tem a ver com o meu interesse em um conhecimento situado e corporificado tal qual o discutido por Donna Haraway em Saberes Localizados: a questão da ciência para o feminismo e o privilégio da perspectiva parcial (1995), cuja explicação sobre o objeto de conhecimento nos saberes localizados é, para mim, também bastante válida:

Saberes localizados requerem que o objeto do conhecimento seja visto como um ator e agente, não como uma tela, ou um terreno, ou um recurso, e, finalmente, nunca como 
um escravo do senhor que encerra a dialética apenas na sua agência e em sua autoridade de conhecimento "objetivo". (1995, p. 36)

Foi ouvindo e vendo os trabalhos de Tássia Reis, Preta Rara e NegaFya que percebi um caminho para minha própria vida, em um momento em que passei a pensar mais criticamente sobre mim e sobre minha condição de mulher negra. Um momento de compreensão de que minha infância, adolescência e vida adulta, assim como a de muitas mulheres pretas foram marcadas por uma percepção: a de que somos vistas como "Outro", e que essa "Outridade", tipo de ausência dupla, posição ocupada por sermos consideradas a antítese da branquitude e da masculinidade, como diz Grada Kilomba (2019), tem impactado tanto nossa mobilidade social, quanto nossos afetos. Esse estado de ausência dupla é, portanto, combatido tanto em trabalhos artísticos como os delas, quanto em trabalhos acadêmicos como o meu, cujo interesse está centrado na expressão de uma existência negra feminina distanciada da ideia de um eu desqualificado.

Nos trabalhos artísticos das minhas sujeitas, por exemplo, pude identificar o princípio da reivindicação do respeito para a mulher negra, por meio da elevação da autoestima e da autodefinição. Patricia Hill Collins em $O$ 
poder da autodefinição (2019), ilustra a importância da autovalorização. Vale a pena conferir o que ela diz:

A ênfase das pensadoras feministas negras na questão do respeito ilustra a importância da autovalorização. Em uma sociedade na qual ninguém é obrigado a respeitar as mulheres afro-americanas, há muito advertimos umas às outras da importância do respeito próprio e do respeito aos outros. $(2019$, p. 207)

Foi assim que compreendi que, para nós, mulheres negras, não há outra saída, senão registrar as nossas falas e reescrever as nossas histórias, independente da forma como isso seja feito. Essas artistas situam os corpos femininos negros e suas subjetividades no centro dos seus discursos, através dos seus próprios versos e performances. Ao lê-las, busco responder se essas produções configuramse como um pensamento feminista-negro capaz de serem denominadas Rimas negro-feministas, um pensamento teórico-crítico sobre uma filosofia de si, tecida pela expressão de subjetividades numa rima que atualiza tal filosofia, um rima que não está imbricada na noção tradicional de rima, mas amalgamada ao corpo feminino negro, suas próprias demandas de (re)existência e expressões, uma rima distante, até mesmo da feitura poética do homem preto, uma rima que rima com as vidas, os corpos, os amores e as raivas das mulheres negras. É, pois, contra toda a brutalidade 
e desumanização das mulheres negras que as produções dessas artistas parecem estar comprometidas.

Desse modo, o operador teórico-crítico Rimas negrofeministas demarca os dois grandes investimentos do meu trabalho, cujo teor é antirracista e feminista: a denúncia do racismo e do sexismo, e a abordagem das subjetividades negras.

Admito que teorizar a experiência de ser negra, em um país que apregoa a falsa existência de uma democracia racial, é uma experiência difícil. Em minha escrita, procuro teorizar, olhando para a produção artística de mulheres negras parecidas comigo, e observando quais resignificações, no âmbito das nossas subjetividades, são feitas a partir das representações que essas produções apresentam.

Consigo identificar esse investimento, por exemplo, quando Preta Rara faz questão de reafirmar a sua humanidade na canção "Negra sim!", dizendo: “[...] Eu tenho alma e coração e não sou feita só de bunda." (2015, faixa 4). Ou quando Nega Fya, em "Preta Escamada", canta os seguintes versos reafirmando que ela é gente: "Preta como a noite, linda e reluzente / cês sabem que a rainha Fya aqui é gente." (2019). Nessa mesma linha de afirmação de humanidade, em "Preta D+", título dado a uma de suas canções, Tássia Reis busca eliminar a negatividade imposta ao fato de ser preta 
demais. A mesma negatividade expressa na pergunta feita pela minha avó materna no dia em que nasci: "que menina preta é esta?". O brado de Tássia é poderoso: "Eu já mudei minha percepção / Agora eu sou preta demais / Mas, não na sua conotação / Eu sou demais, eu sou incrível / Eu sou demais e não sou invisível [...] Eu sou preta demais / Eu sou preta demais / Eu sou preta demais / Eu sou, preta, preta, preta, preta [...]" (2019, faixa 11$)$.

Se você observar e escutar essas artistas com atenção, Marília, perceberá que o que elas dizem e a forma como elas se comunicam comigo atendem a uma perspectiva interseccional, aquela que segundo Kimberlé Crenshaw (2002), intelectual negra estadunidense, busca "[...] capturar as consequências estruturais e dinâmicas da interação entre dois ou mais eixos da subordinação" (2002, p. 177). $\mathrm{Na}$ íntegra desses três trabalhos que citei, anteriormente, por exemplo, há marcadores de classe, de gênero e de raça. Como você sabe, muitas das reflexões feitas por mim, nas sessões, as faço a partir dessas avenidas identitárias que também me atravessam. Quando observo as opressões que experimentei e ainda experimento, por ser mulher e negra, e assumo um trabalho como este, percebo que eu estou me posicionando contra a cidadania de terceira categoria que tentam nos relegar. Carla Akotirene (2018), que atualizou 
o termo proposto por Crenshaw diz que a interseccionalidade "[...] nos coloca na encruzilhada do pensamento feminista negro" (2018, p. 81). Pensando nisso, afirmo que é nessa encruzilhada que estou, analisando as consequências específicas raciais e gendradas, a fim de deixar vir à tona os aspectos chave da subordinação interseccional, e faço isso lendo criticamente as produções a partir das minhas experiências. Pra mim, isso é muito importante. Pra mim, isso é pessoal, e é político. Pra mim, é uma questão de sobrevivência.

Sabe, Marília, a sua provocação me instiga a pensar sobre o tipo de conhecimento que tenho produzido e quais as ultrapassagens de trompas venho realizando, com este meu trabalho, no campo da Teoria da Literatura. É preciso dizer que durante muito tempo a Literatura observou, categorizou e violentou gente como eu, impedindo que escrevêssemos a nossa história, impedindo que fossemos vistas como seres humanos, como escritoras. Por isso, a minha escrita tem importância. Ela nos valida como seres humanos.

Assim, escolhi escrever a minha tese em primeira pessoa e consciente de que há muito sobre o que eu preciso falar e desejando romper com a falsa dicotomia teoria versus prática, escolhi também não isentar meu corpo nesta escrita, lembrando o alerta de Gloria Anzaldúa: “O perigo 
ao escrever é não fundir nossa experiência pessoal e visão do mundo com a realidade, com nossa vida interior, nossa história, nossa economia e nossa visão" (2000, p. 233). Ainda, seguindo os passos de uma mais velha, a escritora Conceição Evaristo, e tentando responder à pergunta feita por ela: “É preciso comprometer a vida com a escrita ou é o inverso? Comprometer a escrita com a vida?" (2007, p. 17) tento apresentar, com o meu trabalho, a minha escrevivência ${ }^{1}$, pois o nosso ponto de vista expresso em produções artísticas e/ou intelectuais nunca estão divorciadas de quem somos.

Incluir o pessoal e o subjetivo como parte do discurso acadêmico é um desafio que pesquisadoras como eu têm encarado, pois, por muitos anos, a única pessoalidade e subjetividade aceita na academia era aquela produzida pelo sujeito branco. É por isso que nossos trabalhos são constantemente considerados não muito científicos e sujeitos a opiniões e questionamentos que servem para desqualificá-los. Ao pensar sobre nossas vozes dentro do contexto acadêmico, Grada Kilomba diz:

Não é que nós não tenhamos falado, o fato é que nossas vozes, graças a um sistema racista, têm sido sistematicamente desqualificadas, consideradas conhecimento inválido; ou então representadas por pessoas brancas que,

1 Termo cunhado pela escritora Conceição Evaristo para se referir ao gesto de escrita, insubordinado, das mulheres negras, que se dá por meio das autoinscrições das suas histórias e subjetividades. 
ironicamente, tornam-se 'especialistas' em nossa cultura, e mesmo em nós. $(2019$, p. 51)

Assim, nossas inseguranças diante daquilo que escrevemos não é coisa que nasce da nossa cabeça, são resultados de violências como essa que acabei de pontuar, e o mais curioso é que nem mesmo o acesso a lugares e aos títulos da branquitude nos livra dessa marca desviante que o racismo nos impõe. Audre Lorde, sabiamente, nos alertou sobre isso, dizendo que "as ferramentas do senhor nunca derrubarão a casa-grande" (2019, p. 137) pois elas nos permitem vencer em seu próprio jogo, mas não nos permitem que provoquemos uma mudança autêntica. Por isso, a importância de nos unirmos para construir novos mundos, onde nossas vozes sejam ouvidas fora da casagrande. Por isso, é tão urgente que comuniquemos nossas ideias fora das estruturas vigentes. Na minha tese, faço isso propondo uma estrutura que faz alusão a um álbum musical. A introdução é prelúdio, as seções são faixas e as referências, ficha técnica, mas não só. Na minha tese abro mão de uma estrutura engessada, que me obriga a escrever com certa impessoalidade, para contar as minhas histórias, fazendo delas dispositivos teórico-críticos.

Confesso que já senti muito medo de ter o meu trabalho desqualificado. Na academia, qualquer fato vinculado a 
quem eu sou ou à minha pesquisa pode ser um motivo de deslegitimação. O fato de não ser uma profissional da música e estar pesquisando nesse campo, por exemplo, por diversas vezes me trouxe certa insegurança diante do meu trabalho. Foi a partir deste estado de insegurança que passei a refletir sobre como foi que me atrevi a escrever sobre música. Sabe, Marília, acho que tenho a resposta para essa pergunta, e ela surge também em uma sessão contigo. Outro dia você chamou atenção para o fato de eu demonstrar bastante apreço pela arte e foi citando as evidências. Neste exato momento, lembro-me que essa minha inclinação pela arte já se manifestava há alguns anos. Em um determinado momento escrevi críticas sobre filmes, livros e músicas, em um blog pessoal intitulado Várias partes de mim. Lembro que na época em que escrevi nesse blog eu não me sentia tão insegura quanto hoje. Preciso saber o que mudou de lá para cá. Desconfio que isso tem a ver com o fato de que a crítica legitimada na academia é uma crítica tida como universalizada, e que não considera saberes produzidos por pessoas como eu, mas apenas mantem posições hierárquicas e preservam a supremacia branca.

Muitas vezes, mesmo desenvolvendo trabalhos que tentam reverter parâmetros e definições disciplinares restritos, ainda assim, escorregamos na casca da banana e 
titubeamos diante da autoridade que temos. Recentemente, numa das aulas ministradas pela professora Laila Rosa, na disciplina Introdução aos Estudos de gênero, relações étnico-raciais, corpo e sexualidade, oferecida pela Escola de Música da UFBA, fiz uma fala que me colocava numa condição de pessoa "desautorizada" a falar sobre música. Fiz isso me baseando no fato de não ser uma profissional do campo musical. Ainda bem que a professora fez questão de discordar de mim, dizendo: "Você é de música sim. Saia do armário!". Naquele momento decidi não mais alimentar o equívoco de que a legitimação das pesquisas sobre música é algo exclusivo dos profissionais da música, pois, superar essa ideia é um passo fundamental para que eu acredite na minha potência de leitura crítica diante da música, e diante das vitais experiências que ela nos proporciona.

Compreender uma música significa compreender a própria vida. Há alguns dias assisti ao filme $A$ voz suprema do blues (2020), dirigido por George C. Wolfe. É uma adaptação da peça teatral de August Wilson, que conta a história de Ma Rainey, a mãe do blues, uma mulher negra que se posicionava de forma contundente diante do controle e da exploração que seus empresários brancos tentavam estabelecer. Uma das falas de Ma, interpretada 
por Viola Davis, reafirma sobre o papel da música na compreensão das nossas experiências. Dizia ela: "Você não canta para se sentir melhor. Canta, porque é um modo de entender a vida". No rastro desse pensamento, afirmo que eu não escuto Tássia Reis, Preta Rara e Nega Fya para me sentir melhor. Eu as escuto porque é um modo de entender a minha vida e a de muitas pessoas negras. Assim como Ma atribuía ao blues o fato de conseguir se levantar da cama todas as manhãs, e consciente de que a música acrescenta algo a mais no mundo, considero o trabalho dessas artistas uma importante arma para minha sobrevivência, pois expressam o acalanto e a resistência de que tanto preciso para sobreviver. O trabalho artístico dessas mulheres fazem política e sustentam os letramentos de reexistência termo cunhado por Ana Lúcia Silva Souza (2011) e que trata das concepções de aprender e de ensinar próprias - , ao contestar o racismo, o sexismo, e as desigualdades sociais. Não sei se já te falei, mas a minha relação com a música, por um momento da minha vida, teve a negativa interferência dos discursos religiosos, os quais me impediram de consumir produções artísticas que não faziam parte da tradição cristã. Esse nocivo discurso, carregado de estereótipos, foi responsável por produzir o meu afastamento de alguns estilos de música. O rap foi um deles. Se a música é também 
base para a constituição das nossas subjetividades e nossas identidades, ter sido privada do seu acesso significa ter sido privada da minha própria experiência existencial e corporal. Outro dia, revendo as cartas que recebia de Tamires Borges, amiga da época da adolescência que havia se mudado para a capital baiana, e que me falava sobre sua identificação com o movimento Hip-Hop e sobre rappers e grupos que estava conhecendo, percebi que eu vivi entre uma disputa de discurso. De um lado, Tamires citava 2Pac, os grupos Racionais MC's e 509-E, referências que eu desconhecia completamente. De outro lado, a igreja me proibia de escutar música "do mundo". Nesse sentido, não é à toa que um dos meus gestos como pesquisadora inserida neste trabalho, tem a ver com a posição que dou ao "eu". Ele está no centro da análise. O uso do pronome em primeira pessoa tem como objetivo combater nosso silêncio secular, e ao mesmo tempo, expressar o processo de busca de uma voz autônoma - parte essencial de um discurso libertador.

Assim, colocando-me no lugar de interlocutora das produções dessas artistas, procuro fazer uma leitura crítica que ultrapasse a leitura simplória e restrita em dizer se as imagens são boas ou ruins, como nos ensina bell hooks, em seu texto $A$ política de libertação: verbalizar este anseio (2019), que "[...] fazer mais do que avaliar positivamente 
esses trabalhos, e que abordá-los de forma crítica, com rigor, demonstra mais respeito do que aceitá-los passivamente" (2019, p. 42).

Considero que o discurso empreendido pelas artistas estudadas parte do pensamento feminista negro. Elas traduzem as necessidades de outras mulheres em um discurso que empreende um fortalecimento, exercendo com afinco e compromisso político o papel de intelectuais. São discursos que tratam de denunciar as imagens de controle sobre nossos corpos.

Winnie Bueno, ao abordar sobre tais imagens, no texto A resistência às imagens de controle a partir do ponto de vista autodefinido (2020), afirma que "[...] retratar pessoas negras como empregados fiéis, abnegados, dependentes e enternecidos pelos seus senhores tem sido uma representação constante nas narrativas populares e acadêmicas nas Américas." (2020, p. 130). Esse tipo de representação das pessoas negras é questionado na canção "Shonda Remix" (2019) de Tássia Reis quando Preta Ary pergunta: “A preta no topo é problema?” (2019, faixa 3). Nessa pergunta, de uma maneira muito direta, há um abalo da concepção de mulher negra presente no imaginário brasileiro de que o topo não é o nosso lugar. 
Em "Falsa abolição" (2015), Preta Rara também denuncia uma imagem de controle, aquela advinda da negação e dos lugares que nos são reservados historicamente, afirmando: “[...] Na novela sou empregada / Da globo sou escrava / Não me dão oportunidade aqui pra nada." (2015, faixa 6). Ainda nessa mesma linha, no prelúdio da declamação do poema Brasil Genocida (2018), Nega Fya, cantando, denuncia o controle que é exercido sobre os nossos corpos, no campo da ciência: "Racistas, querem meu corpo pra estudo / Racistas, só visam o lucro/E eu ainda tô em busca da minha humanidade" (2018).

Sabe, Marília? Helen Campos Barbosa, pesquisadora que estudou as estratégias políticas de mulheres compositoras a partir de uma relação entre saberes, poderes e as nossas subjetivações (práticas de si), propondo um olhar voltado à construção de uma imaginação auditiva, afirma algo que concordo plenamente. Ela diz: "A voz de quem canta não prescinde um corpo, sobre o qual existe uma escrita, passível de reescritas". (2017, p. 123). Colocando-me no lugar de interlocutora das produções dessas artistas, também entendo a necessidade de compreender que a minha escuta é afetiva e também possui um corpo. Nesse sentido, o trabalho dessas artistas inscrevem saberes também no meu próprio corpo, ressuscitando em mim uma experiência corporal neutralizada 
pela religião, pelo racismo e pelo sexismo. Leda Martins, em Performances do tempo espiralar (2002), nos ensina: o corpo é local de inscrição de um conhecimento que se grafa no gesto, no movimento, na coreografia, na superfície da pele, assim como nos ritmos e timbres da vocalidade. Pensando nisso, entendo que o meu trabalho reforça um alargamento da noção de escrita, de literatura e de poesia e tenta contribuir com o combate à ideia hierarquizada contida nos campos de conhecimento, campos disciplinares restritos que nos categoriza e nos atribui estereótipos, sem considerar as nossas produções, nossos modos de fazer arte e teoria e nossos modos de sentir, de escutar e de ler.

O meu texto, assim como as produções das minhas sujeitas de pesquisa, procura, sobretudo, ser político e desprendido de um olhar de mundo que nega o meu valor, que me reserva o lugar de "Outro". Portanto, escutar essas mulheres é como escutar e reescrever a minha própria história. Essas produções alimentam minha potência de viver e agir no mundo, construindo possibilidades de afeto e me fazendo compreender o seu efeito em minha vida. Quer importância maior que esta para um trabalho feito por uma mulher negra para outras mulheres negras? 
Finalizo esta carta, agradecendo a sua sugestão-desafio, pois, se em mim existe um medo de escrever sobre o meu trabalho, ela me ajuda a dissipá-lo, e se existe em mim uma voz soterrada, ela me ajuda também a desenterrá-la.

\section{Com coragem,}

Glauce.

\section{REFERÊNCIAS}

ANZALDÚA, Gloria. Falando em línguas: uma carta para as mulheres escritoras do terceiro mundo. Revista Estudos Feministas, Ano 8, 1으 semestre, p. 229-235, 2000.

AKOTIRENE, Carla. O que é interseccionalidade? Djamila Ribeiro (Coord.). Belo Horizonte: Justificando 2018.

A VOZ SUPREMA DO BLUES. Direção: George C. Wolfe. Roteiro: Ruben Santiago-Hudson. Produção: Todd Black, Denzel Washington e Dany Wolf, 2020. (94 min), son., col. Legendado, port.

BARBOSA, Helen Campos. A experiência estética e as visibilidades de gêneros. Revista de estudos indisciplinares em gêneros e sexualidades, Salvador, v.1, n. 6, p. 110-124, 2017.

BRASIL Genocida. Poesia e performance: Nega Fya, 2018. Disponível em: https://www.youtube.com/watch?v=XAnHbjt6xoM. Acesso em: 29 set. 2020.

COLLINS, Patricia Hill. O poder da autodefinição. In: O pensamento feminista negro: conhecimento, consciência e a política do empoderamento. Tradução de Jamille Pinheiro Dias. São Paulo: Boitempo, 2019.

CRENSHAW, Kimberlé. Documento para o encontro de especialistas em aspectos da discriminação racial relativos ao gênero. Tradução de Liane Schneider. Documento para o encontro de especialistas. Revista Estudos feministas, 2002. 
CUTI. Quebranto. Negroesia: antologia poética. 2. ed. Belo Horizonte: Mazza Edições, 2010.

EVARISTO, Conceição. Da grafia-desenho da minha mãe, um dos lugares de nascimento de minha escrita. In: ALEXANDRE, Marcos Antônio (Org.). Representações performáticas brasileiras: teorias, práticas e suas interfaces. Belo Horizonte: Mazza Edições, 2007.

KILOMBA, Grada. Memórias da plantação - Episódios de racismo cotidiano. Tradução de Jess Oliveira. Rio de Janeiro: Cobogó, p. 248, 2019. HARAWAY, D. Saberes localizados: a questão da ciência para o feminismo e o privilégio da perspectiva parcial. Cadernos Pagu, Campinas, SP, n. 5, p. 7-41, 2009. Disponível em: https://periodicos. sbu.unicamp.br/ojs/index.php/cadpagu/article/view/1773. Acesso em: 29 set. 2020.

HOOKS, bell. A política de libertação: verbalizar este anseio artistas, procuro. In: HOOKS, bell. Anseios: raça, gênero e políticas culturais. Tradução de Jamille Pinheiro. São Paulo: Elefante, 2019.

LORDE, Audre. Olho no olho: mulheres negras, ódio e raiva. In: LORDE, Audre. Irmã Outsider. Tradução de Stephanie Borges. Belo Horizonte: Autêntica Editora, 2019.

LORDE, Audre. As ferramentas do senhor nunca derrubarão a casagrande. In: LORDE, Audre. Irmã Outsider. Tradução de Stephanie Borges. Belo Horizonte: Autêntica Editora, 2019.

PRETA Escamada. Poesia e performance: Apresentação da poeta Nega Fya de Salvador, BA no Slam A Rua Declama em Timóteo, interior de MG. A rua declama, 2019. Disponível em: https://www.youtube.com/ watch?v=H1sHEUWUOjM. Acesso em: $28 \mathrm{dez} .2020$.

RAMOS, Alberto Guerreiro. (1982). II O Negro desde dentro. In: Introdução crítica à sociologia brasileira I. Rio de janeiro: Editora UFRJ, 1995.

RARA, Preta. Falsa abolição. Direção musical: OQ Produções; 2015, Faixa 6 (5 min). Disponível em: https://www.youtube.com/ watch?v=9977Wwnl H8. Acesso em: 29 set. 2020. 
RARA, Preta. Negra sim!. Direção musical: OQ Produções; 2015, Faixa 4 (3 min). Disponível em: https://www.youtube.com/watch?v=sNSW XWmfT8. Acesso em: 28 dez. 2020.

REIS, Tássia. Preta D+. Composição: Tássia Reis. Produção: Eduardo Brechó, 2019, Faixa 6 (3 min). Disponível em: https://www.youtube.com/ watch?v=mUqRkttoEzs. Acesso em: 28 dez. 2020.

REIS, Tássia. Shonda Remix. Composição: Tássia Reis. Participação: Froid e Preta Ary. Produção: Eduardo Brechó, 2019, Faixa 4 (4 min). Disponível em: https://www.youtube.com/watch?v=3vyBIOREpHc. Acesso em: 28 dez. 2020.

SOUZA, Ana Lúcia Silva. Hip-hop: uma produção cultural da diáspora negra. In: Letramentos de (re) existência: poesia, grafite, música, dança: HIP-HOP / São Paulo: Parábola Editorial, 2011.

\section{Glauce Souza Santos}

Doutoranda em Literatura e Cultura (UFBA).

Participa do grupo de Pesquisa: Corpus Dissidente: Poéticas da Subalternidade em Escritas e Estéticas da Diferença.

Lattes: http://lattes.cnpq.br/4102123371619420

E-mail: glaucesouzasantos@yahoo.com.br 